\title{
PERCUTANEOUS NEPHROLITHOTOMY IN FLANK-FREE MODIFIED SUPINE VERSUS PRONE POSITION FOR TREATMENT OF STAGHORN STONES: A PROSPECTIVE RANDOMIZED STUDY.
}

\author{
Ahmed Mohammed El-Sayed Eliwa, Lotfy Abdulatif Bendary, Ashraf Samy Shahin, Mahmoud \\ Mohammed El Adl \\ Urology department faculty of medicine Zagazig University
}

\begin{abstract}
Background: The classic position for percutaneous nephrolithotomy is the prone position as it provide good access to the pelvicalyceal system especially in complex stones such as staghorn stones, however prone position has many limitations especially in morbid obesity and cardiopulmonary problems. Many concerns were made about performing PNL in supine position regarding availability of working space and the possibility of multiple puncture.

Patients and Methods: This is a prospective randomized study that was carried out at urology department Zagazig University in the period from January 2012 till January 2014. The study included 60 patients with staghorn stones scheduled for PCNL and were randomized in two groups using the closed envelope method: Group [A] patients with staghorn stones undergoing PCNL in Flank free modified supine position and Group [B] patients with staghorn stones undergoing PCNL in the standard prone position. Staghorn stone was regarded as any renal stone that occupy the renal pelvis and at least one major calyx. Preplanned tracts were designed according to stone morphology.

Results: Operative time was calculated from the patients positioning for fixing ureteral catheter till the fixation of the nephrostomy. Regarding the operative time the mean operative time in both groups was $94.9 \pm 10.12 \mathrm{~min}$ .In group $\mathrm{A}$ the operative time [96.2 \pm 10.85 minutes] was longer than group $\mathrm{B}$ [93.6 \pm 9.71$]$ however this difference was statistically insignificant $[\mathrm{P}=0.3$ ]. The overall transfusion rate was $5 \%$ [3 patients] two in group $\mathrm{B}$ one in group A. The mean pre-operative Hemoglobin in group A was $12.10 \mathrm{gm} / \mathrm{ml} \pm 0.74$ which turned to $10.75 \mathrm{gm} / \mathrm{ml} \pm 1.07$ postoperatively. Only one patient in this group required blood transfusion [3.3\%]. The mean preoperative Hemoglobin in group $B$ was $12.01 \mathrm{gm} / \mathrm{ml} \pm 0.59$ which turned to $10.83 \mathrm{gm} / \mathrm{ml} \pm 1.05$ postoperatively. Post-operative KUB and U/S was done for all cases to evaluate stone clearance and residual fragments. It was done immediately post-operative day 1 and at the day of discharge. Over-All stone free rate [for both groups] at 24-h was $66.7 \%$ [ 40 patients].The stone free rate at 24-h imaging was higher in group B than in group A $70.0 \%$ [21patients] and $63.3 \%$ [19 patients] respectively however this was statistically insignificant $[\mathrm{p}=0.5]$.
\end{abstract}

Conclusion: Flank free modified supine position during percutaneous nephrolithotomy is safe and effective in treatment of staghorn stone that needs multiple punctures with comparable results to the standard prone position Keywords: staghorn, Flank-free modified supine , percutaneous nephrolithotomy

\section{INTRODUCTION}

T raditionally, PNL [percutaneous nephrolithotomy] has been performed in the prone position. The issues that were raised regarding the prone position include the anaesthetic complications [especially in morbid obesity and skeletal deformity] and the ability to perform concomitant retrograde intra renal surgery, and these were the issues favoring the supine position.

The supine position in spite of being more anaesthetic friendly position and in spite of harboring the ability of performing simultaneous RIRS with sparing operative time for repositioning, issues were raised regarding the number of tracts that can be performed, stone free rate, upper calyceal puncture, and the difficult stone manipulation due to narrow flank space at the supine position [1-10].

Many authors have described PCNL in supine position or its modifications with various types of upper tract stone alone or in conjunction with retrograde intra renal surgery. This lead to a new era in the field of minimally invasive treatment of upper urinary tract stones and the 
appearance of what's known as endoscopic combined intra-renal surgery (ECIRS) [1-10]. The prone position is the most widely used position during PCNL, moreover, its outcome [efficacy, safety, and limitations] have been extensively studied. However, many challenging issues exists, such as the management of high-risk patients with comorbid cardiopulmonary diseases, the need for combined retrograde approach of the upper urinary tract, and the avoidance of musculoskeletal complications led to the development of alternative positions, such as supine (Valdivia) or modified supine (Galdakao modified supine Valdivia position), [1-4] prone flexed, [5] lateral decubitus, [6, 7] reverse lithotomy [8] and the split leg position. $[9,10]$

In our department at Zagazig university we started to practice PCNL in the supine position using the original Valdivia-Uria, and to increase the working space we transferred the ipsilateral flank cushion to the ipsilateral shoulder that lead us to a new position known as the flank-free modified supine position [11].

\section{PATIENTS AND METHODS}

This is a prospective randomized study that was carried out at urology department Zagazig University in the period from January 2012 till January 2014. IRB approval was obtained

Inclusion criteria

Patients with staghorn stones (Stone that involves the renal pelvis and at least one calyx) [Rassweiler et al, 1986] more than $20 \mathrm{~mm}$ in greater diameter before the beginning of the study. The sample size for the present randomized study was calculated using Epi Info 6 version $6.04 \mathrm{~d}$ program software (WHO Geneva) and difference in operative time of $25 \%$ between the two groups was considered as clinical equivalence with confidence of $95 \%$, power of $80 \%$, and Odds Ratio 4.5 depending on De Sio et al., study [14] [at least 36 patients are required for each group]. A p value below 0.05 was considered significant. Data were analyzed using (software SPSS for windows version 10, Chicago, IL, USA). The study included 60 patients with staghorn stones scheduled for PCNL and were randomized in two groups according to patients' registration number [odd number in group A and even number in group B]:

- Group [A] patients with staghorn stones undergoing PCNL in Flank free modified supine position

- Group [B] patients with staghorn stones undergoing PCNL in the standard prone position

Staghorn stone was regarded as any renal stone that occupy the renal pelvis and at least one major calyx.

\section{Exclusion criteria}

Bleeding tendency or anticoagulant therapy

Congenital anomalies of the urinary tract

Any Contraindications to the standard prone position

for PCNL [Severe skeletal deformity, cardiopulmonary morbidity...]

Morbid obesity BMI $>40$

Serum Creatinine $>2 \mathrm{mg} \backslash \mathrm{ml}$
Informed consent was signed by all enrolled patients before surgery after the benefits and risks (including bleeding, infection, and associated organ injury) of the procedure have been explained. Patient's evaluation included history with special attention to: Bleeding disorders, anticoagulant, contrast medium reactions, history of urinary tract infections, history of previous renal surgery, hypertension and diabetes mellitus. Physical examination was done with special attention to:

1) Weight, height and measurement of body mass index.

2) Skeletal deformities.

3) Signs of coagulopathy, anemia and uremia.

4) Scar of previous renal intervention.

5) Organomegally (hepatomegaly or splenomegaly). 
Laboratory investigation included Urinalysis and Urine culture/sensitivity in cases with pyuria (if positive, antibiotic was prescribed for one week preoperatively). Urine cultures were repeated to document sterile urine. Random blood sugar, $\mathrm{CBC}$, coagulation profile kidney function tests were done for all patients

\section{Radiology:}

All patients in the study did KUB, Pelviabdominal US and Non-contrast spiral CT. Stone size was determined by measuring the maximum stone length [longest distance on preoperative CT]. All patients were admitted the day before surgery. All of the procedures were done by the same surgical team, who were already experienced in prone and supine PCNL.

\section{Operative technique:}

Preoperative broad-spectrum antibiotics were administered two hours pre-operative.

Anesthesia: For both groups, Regional anesthesia was performed.

\section{Positioning: \\ In Group A:}

Patients were placed in a Flank free modified supine position by putting the patient in the standard supine position and then fixing ipsilateral arm over the thorax, and crossing the extended patient ipsilateral leg over the contralateral leg. A suitable cushion (3L water bag or less) according to patient body mass under the ipsilateral shoulder, all pressure points were checked carefully and padded [figure 1].
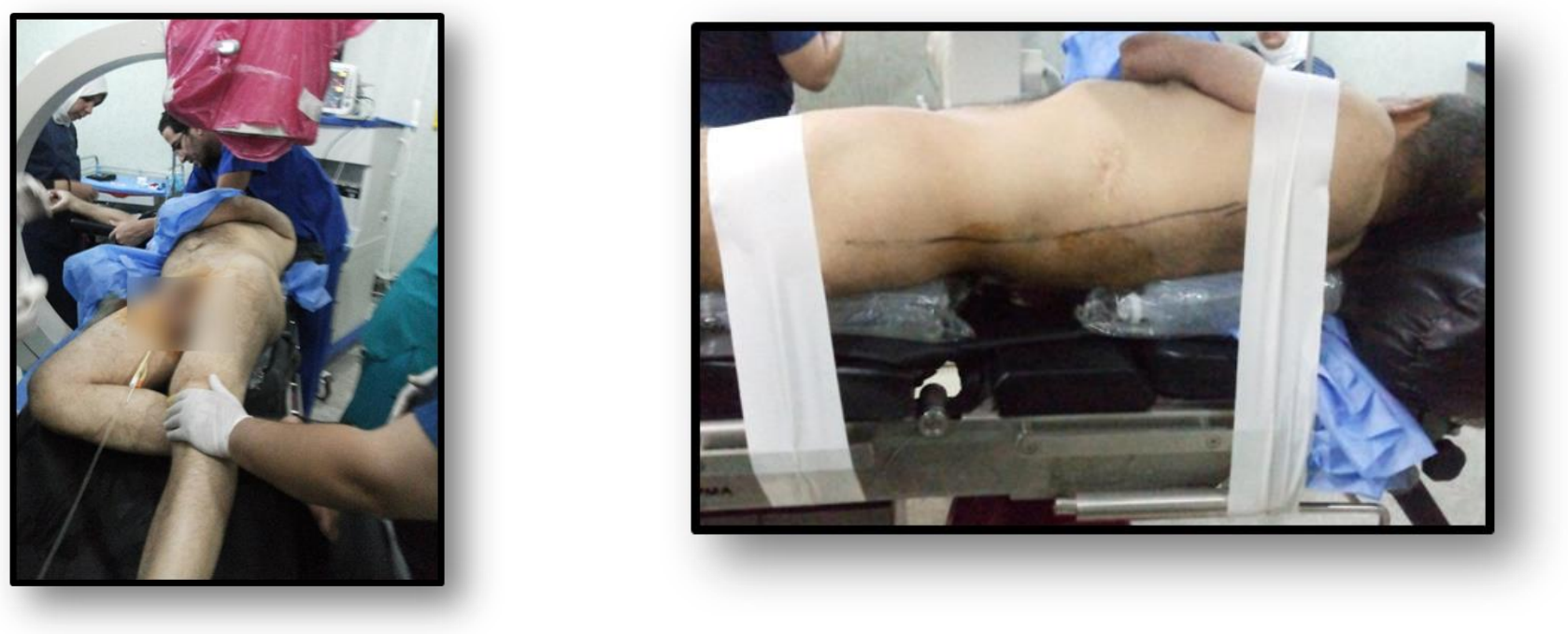

Figure [1]: patient positioning in Flank free modified supine position

\section{In group B:}

Patients were placed in the prone position, and all pressure points are checked carefully and padded. A pillow was placed under the chest and another pillow was placed under the symphysis as a support to allow optimal ventilation.

\section{Technical aspect (in both groups):}

- After reviewing the radiology of each patient; a preplanned tract or tracts are designed along the maximum stone burden so that these tracts are punctured and a safety wires are inserted before dilatation [figure 2]. 

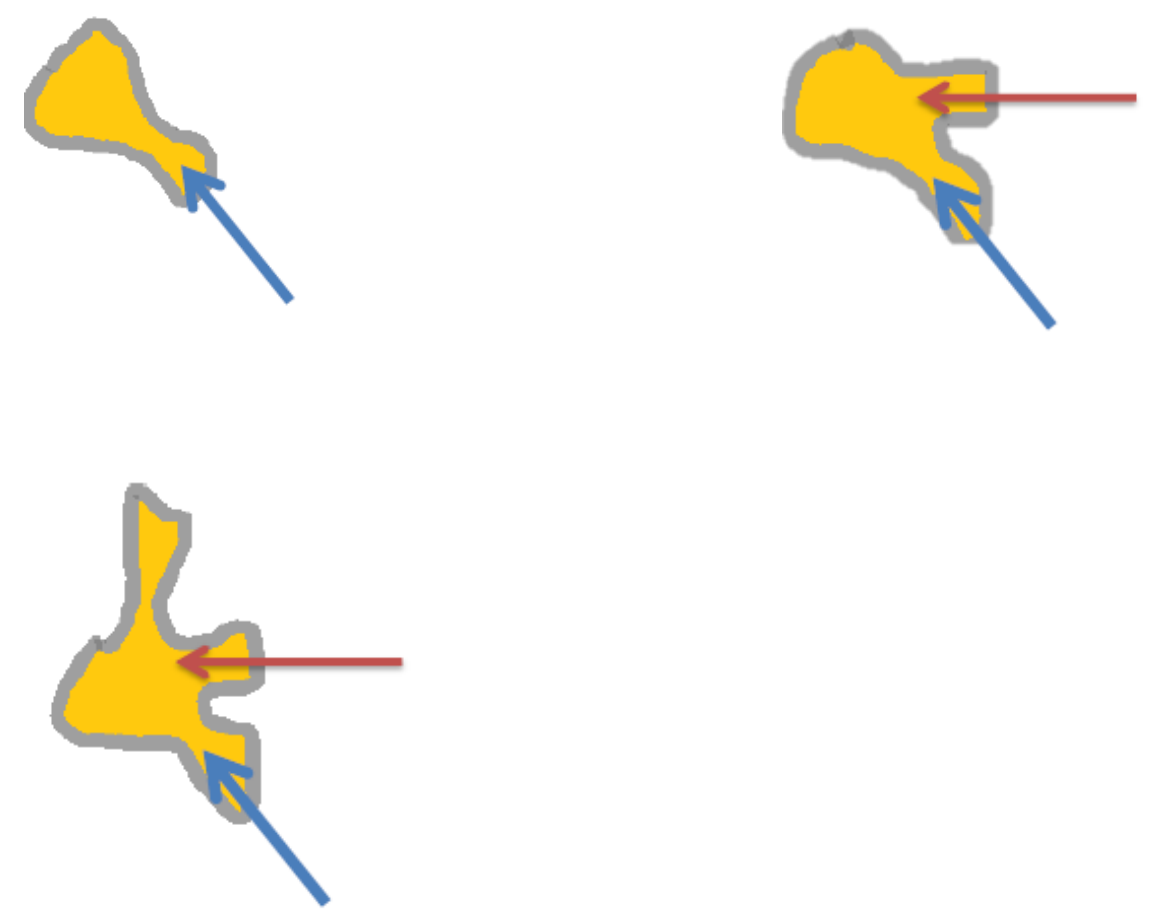

Figure 2 :preplanned tract according to stone morphology

\section{Postoperatively:}

- $\quad$ All patients were observed in the recovery room for 1-2 hours to detect any hemodynamic changes or any postoperative complications. Postoperative CBCs were done for all patients, blood transfusion was needed when HB level was $<8$ gms. /dl

- KUB and US was done in the $2^{\text {nd }}$ postoperative day for evaluation of the residual fragments .The patients is considered free of stone if there was no detected fragments or fragments less than $4 \mathrm{~mm}$ in largest dimensions. Residual fragments measuring 4-10 mm were referred for ESWL.A second session PNL was planned if residual fragment was more than 10 $\mathrm{mm}$ and was performed after $48 \mathrm{~h}$ from the first session. Nephrostomy tube was clamped in the post-operative day one and was removed in the second postoperative day if no second session was planned.

Prophylactic antibiotics were routinely given postoperatively till all tubes are removed and puncture sites healed.

\section{RESULTS}

This study was carried out at urology department Zagazig University from January 2012 till January 2014. The study included 60 patients [see study flowchart] that had staghorn stone \{ stone in the renal pelvis and at least one major calyx $\}$ all of them were scheduled for PCNL as primary treatment option. We had two groups in our study:

Group included 30 patients that underwent PCNL in Flank FREE modified Supine Position [Desoky et al].

Group B Included 30 patients underwent PCNL in the standard prone position 


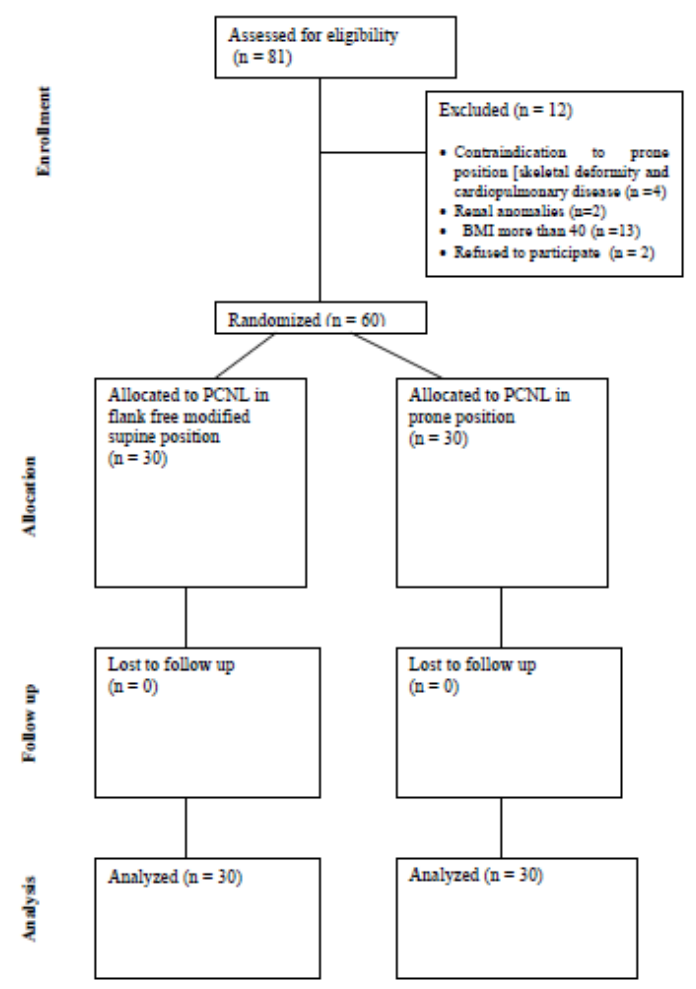

The mean BMI in group A was $29.7 \pm 2.91$ and $29.8 \pm 3.14$ in group B. There was no significant difference in the BMI in Both groups $[\mathrm{P}=0.865]$ Regarding the stone density, taken from the preoperative NCCT study, the mean stone density in group A was 693.5 \pm 181.15 and $702 . \pm 150.57$ in group B, and there was no significant difference in densities in both groups $[\mathrm{P}=0.844]$. Regarding the stone size the mean stone size [the largest stone diameter] of the study groups was $41.63 \mathrm{~mm} \pm 4.5$. In group A the mean stone size was $41.8 \pm 4.2 \mathrm{~mm}$, and $41.46 \pm 5.0 \mathrm{~mm}$ in group $\mathrm{B}$; there was no significant difference between the two groups $[\mathrm{P}=0.7]$ [table [1]].

Table [2] shows surgical outcome in both groups .Operative time was calculated from the patients positioning for fixing ureteral catheter till the fixation of the nephrostomy. Regarding the operative time the mean operative time in both groups was $94.9 \pm 10.12 \mathrm{~min}$.In group $\mathrm{A}$ the operative time [96.2 \pm 10.85 minutes] was longer than group B [93.6 \pm 9.71$]$ however this difference was statistically insignificant $[\mathrm{P}=0.3]$.
The overall transfusion rate was 5\% [3 patients] two in group B one in group A. The mean preoperative Hemoglobin in group A was 12.10 $\mathrm{gm} / \mathrm{ml} \pm 0.74$ which turned to $10.75 \mathrm{gm} / \mathrm{ml}$ \pm 1.07 postoperatively. Only one patient in this group required blood transfusion [3.3\%].The mean preoperative Hemoglobin in group B was $12.01 \mathrm{gm} / \mathrm{ml} \pm 0.59$ which turned to 10.83 $\mathrm{gm} / \mathrm{ml} \pm 1.05$ postoperatively. Regarding the preoperative and postoperative $\mathrm{Hb}$ in $\mathrm{A}$ and $\mathrm{B}$ there were no significant statistical differences between both groups $[\mathrm{P}=0.5$ and $\mathrm{P}=0.7$ respectively].

Regarding the stone morphology, the staghorn stone were classified in both test group into subgroups according to the number and distribution of the stone branches table [3]. After reviewing the patient's radiology, preplanned puncture tracts were designed according to the stone morphology Table [3].

Primary and secondary punctures were made and guide wires were inserted in the preplanned tract. Dilatation of the tract was only made on demand. The figure [3] shows the actual tracts made in each group. 
Table [1] patients and stone Characteristics

\begin{tabular}{llll}
\hline & Group A [FFMS] & group B [prone] & $\mathrm{P}=$ \\
\hline Number & 30 & 30 & \\
\hline Male : female & $24: 6$ & $21: 9$ & 0.8 \\
\hline BMI & $29.7 \pm 2.91 \mathrm{in}$ & $29.8 \pm 3.14$ & 0.8 \\
\hline Stone Density & $693.5 \pm 181.15$ & $702 . \pm 150.57$ & 0.7 \\
\hline Stone size in $\mathbf{m m}$ & $41.46 \pm 5.0 \mathrm{~mm}$ & $41.8 \pm 4.2 \mathrm{~mm}$ & \\
\hline Rt $:$ left & & & \\
\hline
\end{tabular}

Table [2] surgical outcome in both groups

\begin{tabular}{|c|c|c|c|c|}
\hline \multirow{2}{*}{\multicolumn{2}{|c|}{ Number }} & Group A [FFMS] & group B [prone] & $\mathrm{P}=$ \\
\hline & & 30 & 30 & \\
\hline \multicolumn{2}{|c|}{ Op time in minutes } & $96.2 \pm 10.8$ & $93.6 \pm 9.7$ & 0.3 \\
\hline \multicolumn{2}{|l|}{ Pre op Hb } & $12.10 \mathrm{gm} / \mathrm{ml} \pm 0.74$ & $12.01 \mathrm{gm} / \mathrm{ml} \pm 0.59$ & 0.5 \\
\hline \multicolumn{2}{|l|}{ Post op Hb } & $10.75 \mathrm{gm} / \mathrm{ml} \pm 1.07$ & $10.83 \mathrm{gm} / \mathrm{ml} \pm 1.05$ & 0.7 \\
\hline \multirow{2}{*}{$\begin{array}{l}\text { Number } \\
\text { of pre- } \\
\text { planned } \\
\text { tracts }\end{array}$} & 1 & $8[26.7 \%]$ & $12[40.0 \%]$ & 0.2 \\
\hline & 2 & $22[60.0 \%]$ & $18[73.3 \%]$ & \\
\hline \multirow{2}{*}{$\begin{array}{l}\text { Number } \\
\text { of actual } \\
\text { tracts }\end{array}$} & 1 & $14[46.7 \%]$ & $16[53.3 \%]$ & 0.6 \\
\hline & 2 & $16[53.3 \%]$ & $14[46.7 \%]$ & \\
\hline \multicolumn{2}{|c|}{ Transfusion rate } & $3.3 \%$ [one patient] & $6.7 \%$ [ 2 patients] & 0.5 \\
\hline
\end{tabular}

Overall transfusion $5 \%$ [3 patients]

rate

\begin{tabular}{llll}
\hline SFR at 24h imaging & $19[63.3 \%]$ & $21[70.0 \%]$ & 0.5
\end{tabular}

\begin{tabular}{|c|c|c|c|}
\hline Overall SFR at $24 \mathrm{~h}$ & $40[66.7 \%]$ & & \\
\hline $2^{\text {nd }}$ look & $3[10.0 \%]$ & $2[6.7 \%]$ & $\overline{0.6}$ \\
\hline Over all $2^{\text {nd }}$ look & $5[8.3 \%]$ & & \\
\hline SFR at discharge & $21[70 \%]$ & $23[76.7 \%]$ & 0.5 \\
\hline $\begin{array}{lll}\text { Over all SFR at } \\
\text { discharge }\end{array}$ & $44[71.7 \%]$ & & \\
\hline Auxiliary [ESWL] & $8[26.7 \%]$ & $7[23.3 \%]$ & 0.7 \\
\hline Over-all ESWL & $15[25.0 \%]$ & & \\
\hline
\end{tabular}


Table [3] stone morphology in each group

\begin{tabular}{lllll}
\hline $\begin{array}{l}\text { Stone } \\
\text { Morphology }\end{array}$ & Description & Group A & Group B & sum \\
\hline I & $\begin{array}{l}\text { Stone occupying renal } \\
\text { pelvis and one major calyx } \\
\text { [lower calyceal group] }\end{array}$ & $\mathbf{1 2}$ & $\mathbf{2 0}$ \\
\hline II & $\begin{array}{l}\text { Stone occupying renal } \\
\text { pelvis and two major } \\
\text { calyces [lower and middle } \\
\text { calyceal group] }\end{array}$ & $\mathbf{1 6}$ & $\mathbf{3 3}$ \\
& $\begin{array}{l}\text { Stone occupying renal } \\
\text { pelvis and more than two } \\
\text { major calyces [lower } . \\
\text { middle and upper calyceal } \\
\text { group] }\end{array}$ & & \\
& & $\mathbf{2}$ & $\mathbf{7}$ \\
& & $\mathbf{3 0}$ & $\mathbf{6 0}$
\end{tabular}

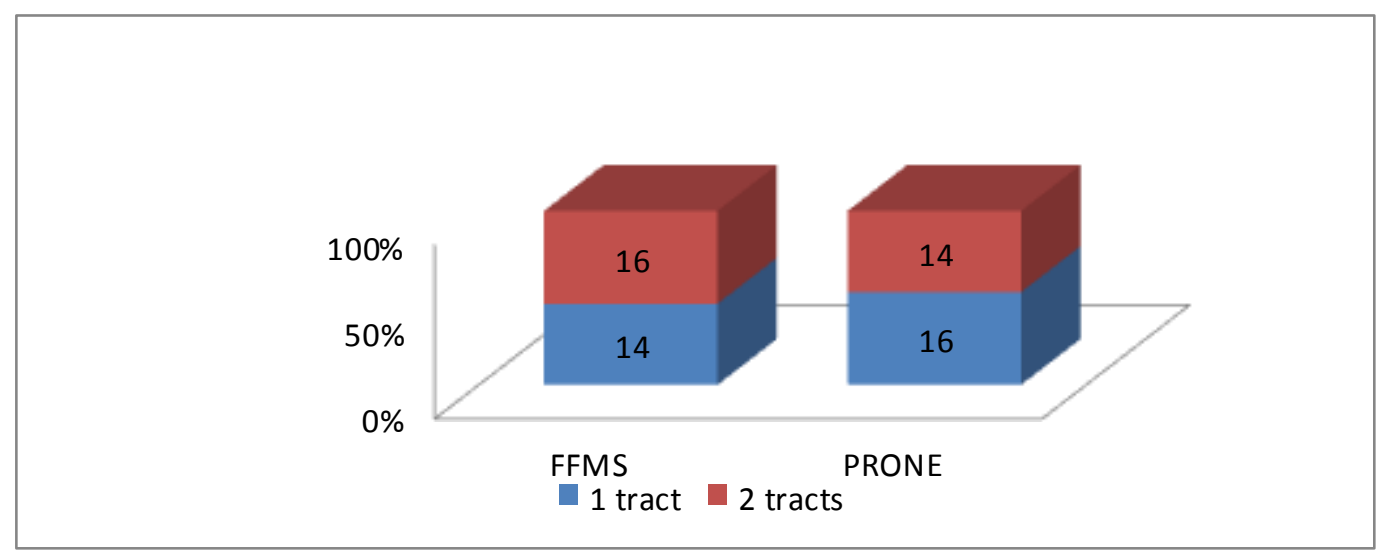

Figure [3 ] : Actual tracts in both groups

$\underline{\text { SFR and Residual stones figure [4,5] }}$

Post-operative KUB and U/S was done for all cases to evaluate stone clearance and residual fragments. It was done immediately postoperative day 1 and at the day of discharge. Over-All stone free rate [for both groups] at 24- h was $66.7 \%$ [ 40 patients]. The stone free rate at 24-h imaging was higher in group B than in group A 70.0\% [21patients] and 63.3\% [19 patients] respectively however this was statistically insignificant $[\mathrm{p}=0.5]$. 


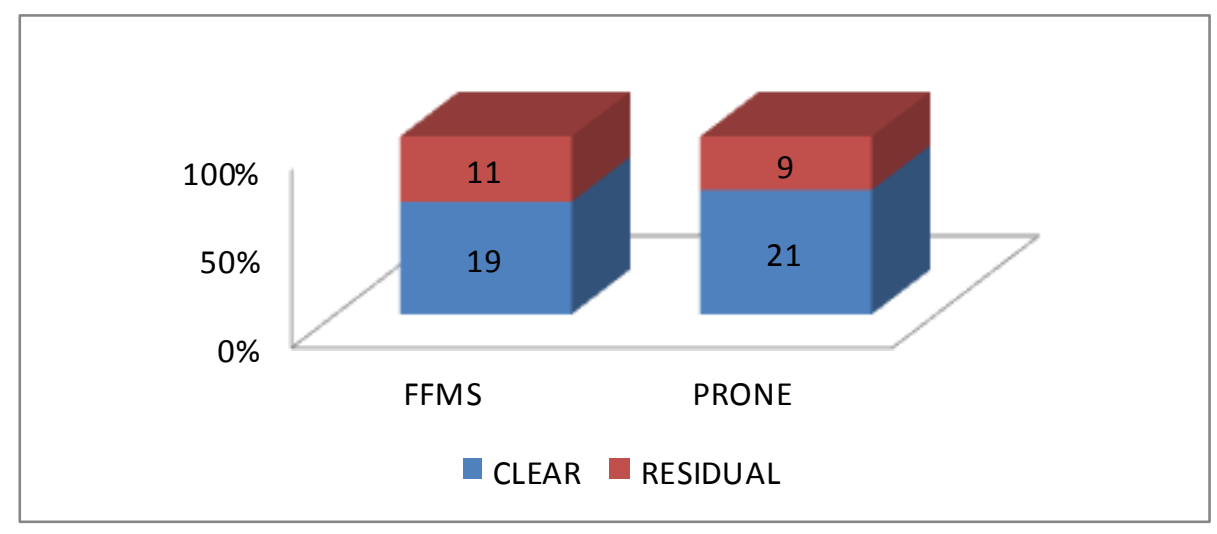

Figure [4] SFR at 24-h image

Over-All stone free rate [for both groups] at discharge was $71.7 \%$ [44 patients] as 4 patients were stone free after the 2 nd look PNL. The stone free rate at discharge was slightly higher at group B than in group A [76.7\% vs $70 \%$ respectively] however this was statistically insignificant $[\mathrm{p}=0.55]$.

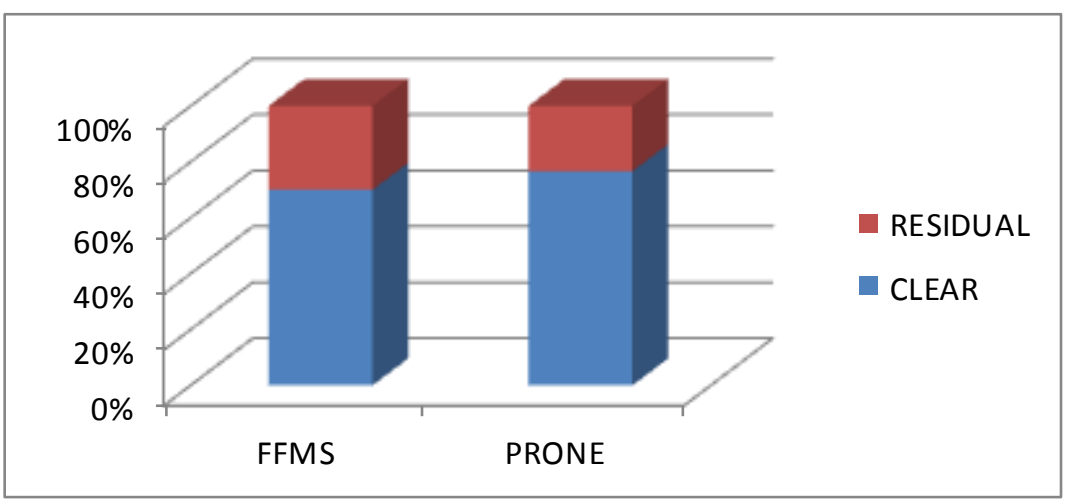

Figure [5] SFR at discharge

2nd look procedure was done in 5 patients $8.3 \%$, [3 in group A and 2 in group B], this lead to increase in the overall stone free rate from $70.0 \%$ at $24-\mathrm{h}$ to $71.7 \%$ at discharge. Fifteen patients [25\%] needed ESWL as an auxiliary maneuver for residual stone, 8 in group $\mathrm{A}$ and $7 \quad$ in group $B$ [ $\mathrm{p}=0.76]$.

Perioperative Complications

The intraoperative complication that was noticed was intraoperative bleeding that was managed by transfusion. Three patients [5\%] had significant intraoperative bleeding two patients in group B and one patient in group A [p=0.55]

The mean preoperative $\mathrm{Hb}$ in group $\mathrm{A}$ was 12.1 $\pm 0.74830 \mathrm{gm} / \mathrm{ml}$ which turned to $10.7 \pm 1.07855$ $\mathrm{gm} / \mathrm{ml}$; while in group $\mathrm{B}$; the mean preoperative $\mathrm{Hb}$ was $12.0 \pm 0.59963 \mathrm{gm} / \mathrm{dl}$ and turned to $10.8 \pm 1.05737 \mathrm{gm} / \mathrm{ml}$ postoperatively. Despite this significant change in the $\mathrm{Hb}$ level postoperatively only three patients required blood transfusion. 
Postoperative pain

Post-operative pain needing parenteral analgesic with bethidine $100 \mathrm{mg}$ was noticed in 16 cases in the supine position and 18 patients in the prone position.

\section{DISCUSSION}

PCNL for decades has been done in the prone position till the contribution of Valdivia et al who first described the supine position in PCNL [1]. The arguments on PNL patient positioning can be attributed to anesthetic considerations, Operative time, visceral injury risk and collecting system access options [feasibility, outcome, and SFR].

The main problem with the supine approach [during PCNL] is that the colon thought to lie at more risk of injury [than the prone position. Boon and colleagues described a risk of colonic injury in supine position to be $16.1 \%$ [descending colon] and $9.0 \%$ [descending colon] at the level of the inferior pole of the kidney [12].

In a systematic review made by Basiri and Sichani, the success rate of the Supine percutaneous nephrolithotomy varies between $69.6 \%$ and $95 \%$ [13].

In our study evaluation of stone clearance was done immediately post-operative day 1 and at the day of discharge. Over-All stone free rate [for both groups] at 24-h was $66.7 \% \quad$ [40

patients]. The stone free rate at 24-h imaging was higher in prone [group B] than in FFMS [group A] 70.0\% [21 patients] and 63.3\% [19 patients] respectively however this was statistically insignificant $[p=0.5]$. Over-All stone free rate [for both groups] at discharge was $71.7 \%$ [44 patients] as 4 patients were stone free after the 2nd look PNL. The stone free rate at discharge was slightly higher at prone [group B] than in FFMS [group A] $[76.7 \%$ vs $70 \%$ respectively] [p=0.55]. No flexible nephroscopy was used as it's not available in our center.

De Sio et al didn't show difference in stone free rate in both supine and prone positions. They had good stone-free rate in both groups $[88.7 \%$ versus $91.6 \%, \mathrm{P}=0.12$ ] in the supine and prone positions respectively [14].
Shoma et al had similar results of PCNL in supine or prone position, respectively. They had overall success rate of $89 \%$ and $84 \%$ in the supine and prone positions, respectively $[\mathrm{p}=$ 0.6]. Second-look PCNL was in $6.5 \%$ and $7.5 \%$ $[\mathrm{p}=1]$ in prone and supine respectively [15].

Desoky et al could not demonstrate significant difference in SFR in both positions as SFR was $84.6 \%$ and $84 \%[p=0.74]$ in supine and prone positions respectively [11]

Perioperative Complications and hospital stay

In a systematic review done by Basiri et al transfusion rate was between zero and $8 \%$. Hospital stay was variable, but it was less than that in the prone position. No colonic perforation was reported [13].

In our study we had intraoperative bleeding requiring transfusion in three patients [5\%], two patients in group B and one patient in group A $[p=0.55]$.grade II According to CLAVIEN-DINDO grading system . The mean hospital stay in our study was $3.4 \pm 1.2$ days and $3.2 \pm 1.01$ days $[p=0.1]$ in FFMS and prone position respectively. We didn't had postoperative urinary leakage this is may be due to the routine use of post procedure double j stent. No cases of organ injuries were reported in our study.

Shoma et al demonstrated the complications in their study that included bleeding i $(4 \%)$ or $(9 \%)$ , urinary leakage (3\%) and (4\%), Fever $\left(\geq 38^{\circ} \mathrm{C}\right) 5 \%$ and $4 \%$ in prone supine position respectively. They had hospital stay of 2.5 and 2.7 days for the supine and prone positions, respectively. No organ injuries were reported in either group. They proposed that the potential disadvantages of the supine position during PCNL were the lateral displacement of the renal puncture would result in difficult renal access and more complications. However their study was none randomized and included both renal and ureteral stones [15].

Astroza et al could no demonstrate significant difference in complication rates between patients with staghorn stones who had PCNL done in prone or supine position $(\mathrm{P}=0.48)$. They found that patients who had multiple renal punctures had significantly more complications 
compared with patients having single puncture. The hospital stay was 5.7 days and 5.2 days for supine and prone, respectively [16].

In the randomized study by De Sio et al; he could not demonstrate any significant difference in hospital stay, complication rate. Neither group required blood transfusion or experienced bowel injury. No chest complications were noted [14].

\section{CONCLUSION}

Flank free modified supine position is safe and effective position during percutaneous nephrolithotomy in treatment of staghorn stone that needs multiple punctures with comparable results to the standard prone position

\section{REFERENCES}

1. Valdivia Uría JG, Valle GJ, López López JA, et al. Technique and complications of percutaneous nephroscopy: experience with 557 patients in the supine position. J Urol. 1998;160:1975-1978.

2. Shoma AM, Erakay I, El-Kenawy MR, et al. Percutaneous nephrolithotomy in the supine position: technical aspects and functional outcome compared with the prone technique. Urology. 2002;60:388-392.

3. Ibarluzea G, Scoffone CM, Cracco CM, et al. Supine Valdivia and modified lithotomy position for simultaneous anterograde and retrograde endourological access. BJU Int. 2007;100:233236.

4. Scoffone CM, Cracco CM, Cossu M, et al. Endoscopic combined intrarenal surgery in Galdakao-modified supine Valdivia position: a new standard for percutaneous nephrolithotomy? Eur Urol. 2008; 54:1393-1403.

5. Ray AA, Chung DG, Honey RJ. Percutaneous nephrolithotomy in the prone and prone-flexed positions: anatomic considerations. J Endourol. 2009;23:1607-1614.

6. Kerbl K, Clayman RV, Chandhoke PS, et al. Percutaneous stone removal with the patient in a flank position. J Urol. 1994;151:686- 688.

7. Gofrit ON, Shapiro A, Donchin A, et al. Lateral decubitus position for percutaneous nephrolithotripsy in the morbidly obese or kyphotic patient. J Endourol. 2002;16:383-386.

8. Lehman T, Bagley DH. Reverse lithotomy, modified prone position for simultaneous nephroscopic and ureteroscopic procedures in women. Urology. 1988;32:529-531.

9. Scarpa RM, Cossu FM, De Lisa A, et al. Severe recurrent ureteral stricture: the combined use of an anterograde and retrograde approach in the prone split leg position without X-rays. Eur Urol. 1997;31:254-256.

10. Grasso M, Nord R, Bagley DH. Prone split leg and flank roll positioning: simultaneous anterograde and retrograde access to the upper urinary tract. J Endourol. 1993;7:307-310.

11. Esam A.E. Desoky *, Mohammed N. Allam, Mostafa K. Ammar, Khaled M. Abdelwahab, Diab A. Elsaid, Amr M. Fawzi, Ahmed A. Alayman, Ashraf M.S. Shahin, Hussein M. Kamel Flank free modified supine position: A new modification for supine percutaneous nephrolithotomy Arab Journal of Urology (2012) 10, 143-148

12.Boon JM, Shinners B, Meiring JH. Variations of the position of the colon as applied to percutaneous nephrostomy. Surg Radiol Anat 2001;23:421-425.

13.Abbas Basiri, Mehrdad Mohammadi Sichani Supine Percutaneous Nephrolithotomy, Is It Really Effective? A Systematic Review of Literature Urol J. 2009;6:73-7.

14. De Sio M, Autorino R, Quarto G et al: Modified supine versus prone position in percutaneous nephrolithotomy for renal stones treatable with a single percutaneous access: a prospective randomized trial. Eur Urol 2008; 54: 196.

15. AHMED M. SHOMA, IBRAHIM ERAKY, MAHMOUD R. EL-KENAWY, AND HAMDY A. EL-KAPPANY PERCUTANEOUS NEPHROLITHOTOMY IN THE SUPINE POSITION: TECHNICAL ASPECTS AND FUNCTIONAL OUTCOME COMPARED WITH THE PRONE TECHNIQUE UROLOGY 60: $388-392,2002$

16. Gaston Astroza, Michael Lipkin, Andreas Neisius, Glenn Preminger, Marco De Sio, Hiren Sodha, Christian Saussine, and Jean de la Rosette, on behalf of the CROES PNL study group Effect of Supine vs Prone Position on Outcomes of Percutaneous Nephrolithotomy in Staghorn Calculi: Results From the Clinical Research Office of the Endourology Society Study UROLOGY 82: 1240e1245, 2013. 